\title{
Manganese Superoxide Dismutase (MnSOD Val-9Ala) Gene Polymorphism and Susceptibility to Gastric Cancer
}

\author{
Mohammad-Taher Moradi ${ }^{1}$, Kheirollah Yari ${ }^{1 *}$, Zohreh Rahimi $^{1}$, Elham Kazemi ${ }^{1}$, \\ Mehrdad Shahbazi ${ }^{3}$
}

\begin{abstract}
Background: Oxidative stress caused by the generation of reactive oxygen species plays an important role in human carcinogenesis. Manganese superoxide dismutase (MnSOD) Val-9Ala in the mitochondrial target sequence is the best known polymorphism of this enzyme. The purpose of the current research was to assess the association of MnSOD Val-9Ala genotypes with the risk of gastric cancer. Materials and Methods: This casecontrol study covered 54 gastric cancer patients compared to 100 cancer free subjects as controls. Extraction of DNA was performed on bioptic samples and genotypes were identified with a polymerase chain reactionrestriction fragment length polymorphism (PCR-RFLP) method. Results: The frequencies of MnSOD Ala/Ala, $\mathrm{Ala} /$ Val and Val/Val genotypes in healthy individuals were $24.3,66.7$ and 9\%, respectively. However, in gastric cancer patients, Ala/Ala, Ala/Val and $\mathrm{Val} / \mathrm{Val}$ were observed in $24.0,48.0$ and $28.0 \%(p=0.01)$. In patients the frequency of MnSOD Val allele was higher $(52 \%)$ compared to that in controls $(\mathbf{4 2} \%)$. Conclusions: The results of this study show a positive association between MnSOD Val-9Ala gene polymorphism and risk of gastric cancer disease in Iranian population.
\end{abstract}

Keywords: MnSOD Val-9Ala - gastric cancer - genetic polymorphism - Iran

Asian Pac J Cancer Prev, 16 (2), 485-488

\section{Introduction}

Gastric cancer (GC) is one of the most important diseases that affected health in all over the world (Zare et al., 2013; Lin et al., 2014). Gastric cancer is the most general deadly cancer with approximately 738,000 deaths per year that over $70 \%$ of them occur in the developing countries (Jemal et al., 2011). Northern and northwestern regions of Iran are high risk areas for gastric cancer (Fallah, 2007; Moradi et al., 2013). Different frequency of gastric cancer in worldwide can be due to variation in the genetic background, dietary habits, living situation and also the prevalence of Helicobacter pylori (H.pylori) infection which has been classified as Group I carcinogens (Humans, 1994). H. pylori infections can induce the host inflammatory responses and oxidative stresses.

Interleukin- 8 is induced by the gastric epithelium cells that infected by $H$. pylori, contributes to the production of too much amounts of toxic reactive oxygen species (ROS) and can causes induction of interferon- $\gamma$ (IFN- $\gamma$ ), tumor necrosis factor- $\alpha$ (TNF- $\alpha$ ) and some other interleukins (Augusto et al., 2007a). Oxidative stress that caused by ROS is involved in human carcinogenesis (Cerutti., 1985). ROS, as candidate agents in the growth of cancer, generated in normal respiration of cells and during xenobiotics metabolism, causes damage to cell membranes, mitochondria and DNA molecule. (Egan et

\section{al., 2003)}

ROS can induce or enable permeabilization in mitochondria, whereas glutathione and antioxidant enzymes reduce it. Some of antioxidant systems are involved in the ROS scavenging, such as the superoxide dismutase or SOD family that catalyzed the dismutation of the superoxide anion to form hydrogen peroxide $\left(\mathrm{H}_{2} \mathrm{O}_{2}\right)$ (Ambrosone et al., 2005). Among SOD family, only manganese superoxide dismutase (MnSOD) is essential for life that as the major antioxidant has a function against ROS or free radicals in the human mitochondria (Sun et al., 1937; Attatippaholkun and Wikainapakul., 2013). The MnSOD protein precursor, with a cleavable mitochondrial targeting sequence or MTS at N-terminal, is synthesized in the cell cytoplasm(Macmillan-Crow and Cruthirds., 2001). A polymorphism in MnSOD (rs4880) gene at the codon 16, that is located at position _9 in the complete protein and results in the substitution of either alanine ( $\mathrm{C}$ allele) or valine ( $\mathrm{T}$ allele) in the mitochondrial targeting sequence. This gene polymorphism of MnSOD is predicted to change the MnSOD secondary structure and may influence the efficiency for MnSOD mitochondrial transport. (Shimoda-Matsubayashi et al., 1996) Recent studies manifested that the Ala form of MnSOD is targeted into the mitochondria, whereas the Val-containing protein is partially arrested in the inner-mitochondrial membrane. (Sutton et al., 2003) 
However, the association between polymorphisms of the related candidate genes with gastric cancer in different ethnicities has been studied; according to our knowledge, there has been no reported data on the possible association between the polymorphism of MnSOD and gastric cancer among Iranian populations. Thus, the aim of current study was to investigate the MnSOD Val-9Ala genotype distribution and its association with gastric cancer among a sample of the Iranian population for the first time.

\section{Materials and Methods}

\section{Enzyme and reagents}

The GPP DNA isolation kit was purchased from Gen Pajohan, Iran. BSaW I as a restriction enzyme, agarose and polymerase chain reaction (PCR) materials were purchased from Fermentas. Specific primers were synthesized from Cinnaclon, Iran. The other chemicals with analytical grade were from Merck.

\section{Participants}

Gastric biopsies were taken from 52 gastric cancer patients with the mean age of $67.8 \pm 8.8$ years and 100 cancer-free with the mean age of $64.2 \pm 5.1$ years as controls. Control groups and patients were age and sex matched (Table 1). All gastric cancer patients were from the north and northwest provinces of Iran who admitted to the medical sciences clinics between May 2011 and June 2012. All of the patient's samples got before therapeutic actions. The gastric cancer diagnosis was according to standard clinical, radiological and histological parameters and results were analyzed by two experienced endoscopists. All procedures of recent research were accepted and approved by the ethics committee in Kermanshah University of Medical Sciences (Iran). Individuals who contributed to this study signed an informed consent in accordance with the Helsinki II declarations. All patients were informed about the aim and procedures of the research.

\section{DNA isolation}

Genomic DNA was isolated from endoscopic fresh biopsy samples. Tissue specimens were suspended in $550 \mu 1$ of DNA extraction buffer (2mM EDTA, $10 \mathrm{mM}$ Tris- $\mathrm{HCl}(\mathrm{pH} 8.0$ and $400 \mathrm{mM} \mathrm{NaCl})$. The suspension was incubated at $20-30{ }^{\circ} \mathrm{C}$ for $20 \mathrm{~min}$, following the addition of Proteinase $\mathrm{K}$ and SDS (400ng and $0.6 \%$, respectively). Then the solution was incubated at $55^{\circ} \mathrm{C}$ for $15 \mathrm{~h}$ and DNA was extracted with the GPP isolation kit (Gen Pajoohan, Iran). Isolated DNA was stored at $-20^{\circ} \mathrm{C}$ until use.

\section{Quantification of extracted DNA}

Isolated DNA was observed and confirmed by gel electrophoresis on 1\% agarose containing DNA Safe Stain (Invitrogen). The concentration and purity of extracted DNA were analyzed using Nanodrop (Thermo) at wavelength of 260 and $280 \mathrm{~nm}$ and measurement of 260/280 ratio, respectively (Yari et al., 2010; Moradi, 2014).

\section{Analysis of MnSOD Val-9Ala genotypes}

The MnSOD Val-9Ala polymorphism was assessed by PCR amplification and then RFLP analysis. The specific oligonucleotide primers used to amplify as follows: 5'-CGGGCTGTGCTTTCTCGTC-3' (forward) and 5'-TCAGCCTGGAACCTACCCTT-3'(reverse). PCR amplification was carried out in a total volume of $25 \mu 1$ containing $500 \mathrm{ng}$ of genomic DNA as template, $1 \mathrm{x}$ PCR reaction buffer, $\mathrm{MgCl} 2$ with $1.5 \mathrm{mM}, 0.2 \mathrm{mM}$ of dNTPs, $0.5 \mu \mathrm{M}$ of each forward and reverse primers and 2 units of Taq DNA polymerase (Fermentase, USA).

Thermocycler parameters comprised of first denaturation step at $95^{\circ} \mathrm{C}$ for $7 \mathrm{~min}, 35$ cycles of denaturation at $95^{\circ} \mathrm{C}$ for $45 \mathrm{~s}$, annealing at $58^{\circ} \mathrm{C}$ for 45 $\mathrm{s}$, extension at $72^{\circ} \mathrm{C}$ for $45 \mathrm{~s}$, and then a final extension at $72^{\circ} \mathrm{C}$ for $5 \mathrm{~min}$.

After amplification, $12 \mu 1$ of PCR products were subjected to overnight digestion with 10 units of $B S a W$ I (New England Biolabs, Beverly, MA, USA) at $60^{\circ} \mathrm{C}$. Digested PCR products were shown on a $2 \%$ agarose gel stained with Syber safe DNA under ultraviolet light. The patterns of the bands were as follows: 243 bp for Ala/Ala homozygotes; 243, 196, and 47 bp for Ala/Val heterozygotes; 196 , and $47 \mathrm{bp}$ for Val/Val homozygotes. $5 \%$ of the samples were randomly selected and regenotyped for quality control purposes.

\section{Statistical analysis}

All of statistical studies were carried out with statistical software of SPSS (Version 16). Diversity in genetic distributions between control and patient groups was analyzed by Pearson's chi-square $\left(\chi^{2}\right)$ assay. $95 \%$ of confidence intervals $(95 \% \mathrm{CI})$ and Odds ratios (OR) were calculated with an unconditional logistic regression model. Results of this study were considered with statistically significant when $\mathrm{p}<0.05$.

\section{Results}

Some of the personalities of the gastric cancer patients are shown in Table 1. 52 gastric cancer patients and 100 healthy individuals as a control group participated in this study. The control group, $62 \%$ men and $38 \%$ women with the mean age of $64.2 \pm 5.1$ years), were free from cancer signs. Further, the gastric cancer group consisted of $42.3 \%$ women and $57.7 \%$ men with the mean age of $67.8 \pm 8.8$ years. There was no significant difference between patients and controls in terms of age and sex. In all participants, DNA was isolated by the GPP DNA extraction kit as previously mentioned, and quantity and quality of

Table 1. Characteristics of Human Gastric Cancer Patients and Cancer-Free Controls

\begin{tabular}{llr}
\hline Variable & $\begin{array}{l}\text { Patient }(\mathrm{n}=52) \\
\mathrm{n}(\%)\end{array} \mathrm{n}(\%)$ & Healthy control $(\mathrm{n}=100)$ \\
\hline Mean age, years $[ \pm \mathrm{SDa}]$ & $67.8[ \pm 8.84]$ & $64.2[ \pm 5.14]$ \\
Age, years & $1(1.93)$ & $16(16)$ \\
$<50$ & $11(21.15)$ & $66(66)$ \\
$50-65$ & $40(76.92)$ & $18(18)$ \\
$>65$ & $30(57.7)$ & $62(62)$ \\
Males & $22(42.3)$ & $38(38)$ \\
Females & &
\end{tabular}


Table 2. Distribution of MnSOD Val-9Ala Genotypes in Gastric Cancer Patients and Controls

\begin{tabular}{lcr}
\hline & $\begin{array}{c}\text { Case } \\
(\%) \mathrm{n}\end{array}$ & $\begin{array}{c}\text { Control } \\
\mathrm{n}(\%)\end{array}$ \\
\hline $\begin{array}{l}\text { MnSOD genotypes } \\
\text { Ala/Ala }\end{array}$ & $12(24)$ & $19(24.35)$ \\
Ala/Val & $24(48)$ & $52(66.66)$ \\
Val/Val & $14(28)$ & $7(8.97)$ \\
$\chi^{2}=8.51, \mathrm{p}=0.01$ & & \\
MnSOD alleles & & $90(57.69)$ \\
Ala & $48(48)$ & $66(42.04)$ \\
Val & $52(52)$ & \\
$\chi^{2}=2.3, \mathrm{p}=0.12$ & & \\
\hline
\end{tabular}

$\begin{array}{lllll}1 & 2 & 3 & 4 & 5\end{array}$

$196 \mathrm{bp}$

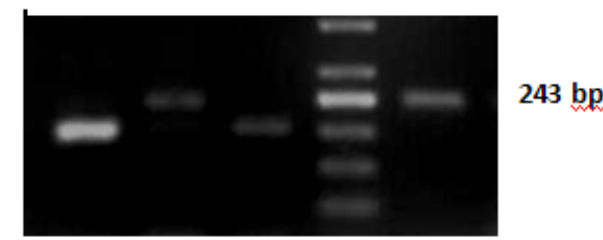

Figure 1.2\% Agarose Gel Electrophoresis of Digested PCR Product by $B S a W$ I Restriction Enzyme. Lane 1 and 3 Show Mutant Genotype, Lane 2 and 5 Demonstrate the Wild Genotype. The 50 bp DNA Molecular Weight Marker is Indicated in lane 4

extracted DNA were evaluated by spectrophotometric assay and gel electrophoresis (result not shown). To investigate the gene polymorphism, PCR-RFLP was carried out.

Distribution of MnSOD genotypes and alleles in gastric cancer patients and controls is shown in Table 2. The frequency of MnSOD Ala/Ala, Ala/Val and Val/Val genotypes in healthy individuals were 24.3,66.7 and 9\%, respectively. However, in Gastric cancer patients, Ala/Ala, Ala/Val and Val/Val with 24, 48 and $28 \%$ were observed $(\mathrm{p}=0.01)$. In patients the frequency of MnSOD Val allele was higher $(52 \%)$ compared to that in controls $(42 \%)$. In both of patient and control groups, the frequencies of MnSOD genotypes were in Hardy-Weinberg equilibrium.

\section{Discussion}

The current research in a homogenous population of gastric cancer patients from north and northwest of Iran reports a significantly higher frequency of Val allele compared to that in healthy individuals that increased the risk of gastric cancer. Gastric cancer is the most frequent malignancy diagnosed in worldwide and it is the most common deadly cancer in Iran. Northern and northwestern regions in Iran are high risk areas for gastric cancer. Epidemiologic studies have reported numerous risk factors for gastric cancer, including environmental, genetic factors, adverse living conditions, dietary habits and the prevalence of Helicobacter pylori (H. pylori) infection (Moges et al., 2006).

Reactive oxygen species (ROS), generated during metabolism of xenobiotics and in normal cellular respiration, causes damage to membranes, mitochondria, and macromolecules including DNA, and thus are candidate agents in the development of human cancer
(Margaret et al., 2011). MnSOD is the important antioxidant agent in the mitochonderia that catalyzes the dismutation of superoxide radicals to hydrogen peroxide form and detoxification of mitochondrial ROS (Sun et al., 2012). The MnSOD gene as tumor suppressor gene is located on chromosome 6 at q25.3. A number of polymorphisms have been reported in the MnSOD gene that some of them are associated with the increased risk of human cancers. Recent studies confirmed functional polymorphism of the Val-9Ala MnSOD that Val allelecontaining precursor protein with beta-sheet conformation exhibited impaired transportation, but Ala-containing precursor with alpha helical conformation showed normal transportation. Therefore, the variant allele (Ala) with higher activity suppresses carcinogenesis. MnSOD polymorphic alleles are widely variable with ethnicity, the frequency of Ala allele is $12 \%$ among Japanese (Shimoda-Matsubayashi et al., 1996) and 14\% in Chinese (Cai et al., 2004), while it is more general (41-55\%) in the population of Caucasian (Ambrosone et al., 1999) and $41 \%$ in Jordanian breast cancer population.

There are several available data to investigate the role of Val-9Ala MnSOD variants in susceptibility to gastric cancer. Similar to our study, Atoum et al. (2012) observed that the Val/Val allele of MnSOD Val-9Ala was correlated to a significantly decreased risk for breast cancer disease in Jordanian population. Also, Augusto et al. (2007b) indicated that gastritis was characteristic by an oxidative stress with significant absence of MnSOD and GPX expression. In meta-analysis that reported by Wang suggest that the MnSOD Val-9Ala polymorphism may contribute to cancer development through a disturbed antioxidant balance (Wang et al., 2009).

In conclusion, in a high-risk gastric cancer area, we examined the relationship between MnSOD Val/Ala polymorphism with the risk of gastric cancer. Our results of this research showed that there was a significant positive association between the distribution of the MnSOD gene polymorphism and gastric cancer disease. In addition, the results show that the polymorphism of MnSOD Val-9Ala is an important risk factor that is associated with gastric cancer in sample of the Iranian population. However, further research with a larger sample size is required to confirm these findings. The present study that reported here is the first published research on the correlation between the MnSOD genotypes and the susceptibility to gastric cancer disease in the Iranian population. This study can be used as a basis for studying polymorphisms of other important genes in correlation to gastric cancer.

\section{References}

Ambrosone CB, Ahn J, Singh KK, et al (2005). Polymorphisms in genes related to oxidative stress (MPO, MnSOD, CAT) and survival after treatment for breast cancer. Cancer Res, 65, 1105-11.

Atoum M, Abdel-Fattah M, Nimer N, Abdel-Rahman S, Abdeldayem SA (2012). Association of alanine-valine manganese superoxide dismutase gene polymorphism and microheterogeneity manganese superoxide dismutase activity in breast cancer and benign breast tissue. $J$ Breast Cancer, 15, 157-61. 
Attatippaholkun W, Wikainapakul K (2013). Predominant genotypes and alleles of two functional polymorphisms in the manganese superoxide dismutase gene are not associated with thai cervical or breast cancer. Asian Pac J Cancer Prev, 14, 3955-61.

Augusto AC, Miguel F, Mendonça S, et al (2007a). Oxidative stress expression status associated to Helicobacter pylori virulence in gastric diseases. Clin Biochem, 40, 615-22.

Augusto AC, Miguel F, Mendonça S, et al (2007b). Oxidative stress expression status associated to Helicobacter pylorivirulence in gastric diseases. Clin Biochem, 40, 61522.

Cerutti PA (1985). Prooxidant states and tumor promotion. Science, 227, 375-81.

Egan KM, Thompson PA, Titus-Ernstoff L, et al (2003). $<\mathrm{i}>\mathrm{MnSOD}</ \mathrm{i}>$ polymorphism and breast cancer in a population-based case-control study. Cancer letters, 199, 27-33.

Fallah M (2007). Cancer Incidence in Five Provinces of Iran: Ardebil, Gilan, Mazandaran, Golestan and Kerman, 19962000.

Humans IWGotEoCRt 1994. Schistosomes, liver flukes and Helicobacter pylori, World Health Organization.

Jemal A, Bray F, Center MM, et al (2011). Global cancer statistics. CA Cancer J Clin, 61, 69-90.

Lin WL, Sun JL, Chang SC, et al (2014). Factors predicting survival of patients with gastric cancer. Asian Pac J Cancer Prev, 15, 5835-8.

Macmillan-Crow LA, Cruthirds DL (2001). Manganese superoxide dismutase in disease. Free Radical Res, 34, 325-36.

Margaret AL, Syahruddin E, Wanandi SI (2011). Low activity of manganese superoxide dismutase (MnSOD) in blood of lung cancer patients with smoking history: relationship to oxidative stress. Asian Pac J Cancer Prev, 12, 3049-53.

Moges F, Kassu A, Mengistu G, et al (2006). Seroprevalence of Helicobacter pylori in dyspeptic patients and its relationship with HIV infection, ABO blood groups and life style in a university hospital, Northwest Ethiopia. World $J$ Gastroenterol, 12, 1957.

Moradi MT (2014). A Novel, efficient, fast and inexpensive DNAextraction protocol from whole blood applicable for studying drug-DNA interaction. J Rep Pharm Sci, 3, 80-4.

Moradi MT, Hashtchin AR, Yari K (2013). Helicobacter pylori cagA-positive strains: gastric cancer susceptibility. Biharean Biologist, 7, 86-9.

Shimoda-Matsubayashi S, Matsumine H, Kobayashi T, et al (1996). Structural dimorphism in the mitochondrial targeting sequence in the human manganese superoxide dismutase gene: a predictive evidence for conformational change to influence mitochondrial transport and a study of allelic association in Parkinson's disease. Biochem Biophy Res Commun, 226, 561-5.

Sun G-G, Hu W-N, Wang Y-D, et al (2012). Bidirectional regulation of manganese superoxide dismutase (MnSOD) on the radiosensitivity of esophageal cancer cells. Asian Pac $J$ Cancer Prev, 13, 3015-23.

Sun G-G, Wang Y-D, Lu Y-F, et al (2013). Different association of manganese superoxide dismutase gene polymorphisms with risk of prostate, esophageal, and lung cancers: evidence from a meta-analysis of 20,025 subjects. Asian Pac J Cancer Prev, 14, 1937-43.

Sutton A, Khoury H, Prip-Buus C, et al (2003). The Ala16Val genetic dimorphism modulates the import of human manganese superoxide dismutase into rat liver mitochondria. Pharmacogenetics, 13, 145-57.

Wang S, Wang F, Shi X, et al (2009). Association between manganese superoxide dismutase (MnSOD Val-9Ala polymorphism and cancer risk-A meta-analysis. Eur $J$ Cancer, 45, 2874-81.

Yari K, Fatemi SSa, Tavallaei M (2010). Optimization of the BoNT/A-Hc expression in recombinant Escherichia coli using the Taguchi statistical method. Biotechnol appl biochem, 56, 35-42.

Zare A, Mahmoodi M, Mohammad K, et al (2013). Survival analysis of patients with gastric cancer undergoing surgery at the Iran cancer institute: a method based on multi-state models. Asian Pac J Cancer Prev, 14, 6369-73. 